\title{
Evaluation of the Antimalarial Activity of the Leaf Latex of Aloe weloensis (Aloaceae) against Plasmodium Parasites
}

\author{
Gedefaw Getnet Amare $\left(\mathbb{D},{ }^{1}\right.$ Amsalu Degu $\mathbb{D},{ }^{2}$ Peter Njogu, ${ }^{3}$ and Zemene Demelash Kifle $\mathbb{I D}^{4}$ \\ ${ }^{1}$ Department of Pharmacy, College of Medicine and Health Sciences, Wollo University, Dessie, Ethiopia \\ ${ }^{2}$ Department of Pharmaceutics and Pharmacy Practice, School of Pharmacy and Health Sciences, \\ United States International University-Africa, Nairobi, Kenya \\ ${ }^{3}$ Department of Pharmaceutical Chemistry, School of Pharmacy, University of Nairobi, Nairobi, Kenya \\ ${ }^{4}$ Department of Pharmacology, School of Pharmacy, College of Medicine and Health Sciences, University of Gondar, \\ Gondar, Ethiopia \\ Correspondence should be addressed to Gedefaw Getnet Amare; gedefawg39@gmail.com
}

Received 27 December 2020; Revised 18 April 2021; Accepted 4 June 2021; Published 16 June 2021

Academic Editor: Rômulo Dias Novaes

Copyright (C) 2021 Gedefaw Getnet Amare et al. This is an open access article distributed under the Creative Commons Attribution License, which permits unrestricted use, distribution, and reproduction in any medium, provided the original work is properly cited.

Background. The lack of available vaccines and the emerging resistance to antimalarial drugs have provided the necessity to find noble antimalarial plant-based medicines. The leaf latex Aloe weloensis has been used in folk medicine against malarial and other human ailments in Ethiopia. Hence, the present study aimed to investigate the antimalarial activity of the leaf latex of $A$. weloensis against Plasmodium parasites. Materials and Methods. The prophylactic and curative models were employed to determine the in vivo antimalarial activity of the leaf latex $A$. weloensis against $P$. berghei infected mice, and the antioxidant activity of the latex was assessed using diphenyl-1-picrylhydrazine (DPPH) assay. Female mice were recruited for toxicity study, and the leaf latex was administered to fasted mice at a dose of $5000 \mathrm{mg} / \mathrm{kg}$. The mice were kept under continuous observation for fourteen days for any signs of overt toxicity. Results. The leaf latex of A. weloensis was safe up to $5000 \mathrm{mg} / \mathrm{kg}$, and the latex endowed free radical inhibition activity $\left(\mathrm{IC}_{50}=10.25 \mu \mathrm{g} / \mathrm{ml}\right)$. The latex of $A$. weloensis leaf demonstrated the inhibitory activity against the 3D7 strain of P. falciparum $\left(\mathrm{IC}_{50}=9.14 \mu \mathrm{g} / \mathrm{ml}\right.$ ). The prophylactic and curative effect of the latex was found to be dose-dependent. The mice's parasitemia level was significantly $(p<0.001)$ reduced at all tested doses of the leaf latex compared to negative control in the curative test. Parasitemia reduction was significant $(200 \mathrm{mg} / \mathrm{kg}, p<0.01$, and 400 and $600 \mathrm{mg} / \mathrm{kg}, p<0.001)$ in the prophylactic test compared to the control. In addition, the leaf latex significantly $(p<0.01)$ improved mean survival time, packed cell volume, rectal temperature, and bodyweight of $P$. berghei infected mice. Conclusion. The leaf latex of Aloe weloensis was endowed with the antimalarial activity at various doses, corroborating the plant's claimed traditional use.

\section{Background}

Plants and plant extracts possess a wide margin of safety and show potential effectiveness in treating various diseases $[1,2]$. Medicinal plants are the primary resource for treating malaria infections in Africa since healthcare facilities are limited [3]. The currently available antimalarial drugs such as quinine, halofantrine, mefloquine, chloroquine, and artemisinin are of plant origin [4-6].

The lack of available vaccines and the emerging resistance to antimalarial drugs have provided the necessity to find noble plant-based antimalarial drugs [7-9]. Developing noble antimalarial agents is imperative to overcome the challenges posed by the development of antimalarial drug resistance. Nature has gifted various plants with a potential effect against Plasmodium parasites [10-12].

Aloe species have been used as topical and oral therapeutic agents due to their health, beauty, medicinal, and skincare properties. They have demonstrated antibacterial, antitumor, anti-inflammatory, antiarthritic, antirheumatoid, anticancer, and antidiabetic activities [13]. The latex of Aloe weloensis leaf showed an antibacterial effect against Gramnegative and Gram-positive strains [14]. The plant's leaf latex has been used in folk medicine against malarial and other 
human ailments in Ethiopia [15]. Previously, the leaf latex Aloe weloensis showed a significant antimalarial effect in Peter's (4-day suppressive) test and safe at $2000 \mathrm{mg} / \mathrm{kg}$ [16]. Besides, phytochemical studies showed that this plant's leaf latex was endowed with flavonoids, glycosides, anthraquinones, saponins, terpenoids, and tannins with prominent antimalarial activities in various plant extracts [12, 17-19]. Eventhough few investigations have been conducted previously, there was a paucity of comprehensive studies in other models (prophylactic and curative models) and in vitro studies (DPPH assay). Therefore, this study was aimed to investigate the antimalarial activity of the leaf latex of A. weloensis against Plasmodium parasites using prophylactic and curative models.

\section{Materials and Methods}

2.1. Collection and Preparation of Leaf Latex of Aloe weloensis. The leaf of $A$. weloensis was collected for identification from northeast Ethiopia (Guba Lafto) in May 2020. The plant was identified by Ms. Habtam G (botanist) with voucher specimen number HG010/20. After identification, the leaf A. weloensis was cut near the stem and inclined towards the collecting plate to gain the latex. The latex was dried under shade at room temperature with optimal ventilation. The dried latex was kept in a clean vial and stored in a dessicator until used for the experiment.

2.2. Experimental Animals and Parasites. Healthy Swiss albino mice of either sex weighing 20-35 grams and aged 2-3 months were used in the study. The mice were obtained from Wollo University, Department of Pharmacology. The mice were kept in plastic cages at room temperature and $12 \mathrm{~h}$ light and $12 \mathrm{~h}$ dark cycle, with free access to pellet food and water in the laboratory $[17,18]$. The mice were acclimatized to laboratory condition for one week before the initiation of the experiment. The P. berghei ANKA strain was obtained from
Ethiopian Public Health Institute, while the 3D7 strain of $P$. falciparum was obtained from Italy. The P. berghei parasite was maintained by serial blood passage from infected mice to uninfected ones on a seven-day basis. This study was carried out based on the guide for the care and use of laboratory animals $[17,20,21]$.

2.3. Acute Oral Toxicity Study. An acute oral toxicity study was carried out based on the Organisation for Economic Cooperation and Development (OECD) guidelines 425 [22]. Female mice were recruited for the toxicity study since they are more sensitive than male mice. One female Swiss albino mouse fasted for $4 \mathrm{~h}$, and the animal's fasting bodyweight was measured [17]. Then, the leaf latex was administered to the mouse at a dose of $5000 \mathrm{mg} / \mathrm{kg}$. The mouse was then kept under strict observation of physical and behavioral changes for one day, with special attention during the first $4 \mathrm{~h}$. Following the result from the first mouse, another four mice fasted for $4 \mathrm{~h}$, and then, the latex was administered to each mouse at the dose of $5000 \mathrm{mg} / \mathrm{kg}$ and was observed in the same manner. The observation was continued for fourteen days for any signs of overt toxicity.

2.4. In Vitro Antioxidant Activity of the Leaf Latex Aloe weloensis. Antioxidant activity of the latex of $A$. weloensis leaf was evaluated using DPPH-free radical scavenging assay following the method of MacDonald-Wicks et al. [23] as previously described by Sanchez-Moreno et al. [24]. A $3 \mathrm{ml}$ of $0.1 \mathrm{mM}$ DPPH in methanol was mixed in $1 \mathrm{ml}$ methanolic solution of different concentrations $(12.5-400 \mu \mathrm{g} / \mathrm{ml})$ of the latex and incubated in the dark for $30 \mathrm{~min}$ at room temperature. Ascorbic acid was used as a standard antioxidant. After $30 \mathrm{~min}$, the absorbance of the mixture and the control at $517 \mathrm{~nm}$ was read by using a UV spectrophotometer. The test was conducted in triplicate, and the percent of scavenging of inhibition was calculated as follows:

$$
\% \text { of free radical scavenging }=\frac{\text { (absorbance of control }- \text { absorbance of sample) }}{\text { absorbance of control }} \times 100 \text {. }
$$

2.5. In Vitro Antimalarial Evaluation of the Leaf Latex of Aloe weloensis. Chloroquine-sensitive 3D7 strain of $P$. falciparum was used to determine the in vitro antimalarial activity of the leaf latex of $A$. weloensis. Plasmodium falciparum culture was maintained following previously described methods with some modifications [19, 25]. Plasmodium falciparum (suspension of 3D7) synchronized in 5\% sorbitol to ring stage was seeded $\left(200 \mu \mathrm{l} /\right.$ well with $2 \%$ ring stages and $\mathrm{O}^{\mathrm{Rh}+}$ red blood cells at $2 \%$ hematocrit) in 96 -well tissue culture plates. The latex of $A$. weloensis leaves in different concentrations $(10-320 \mu \mathrm{g} / \mathrm{ml})$ was added to these wells. The same chloroquine concentration was used as the standard control, and dimethyl sulfoxide was used as the negative control. The parasites were cultured for $30 \mathrm{~h}$ in the desiccator and then incubated $\left(37^{\circ} \mathrm{C}\right)$ for $72 \mathrm{~h}$ in $2 \% \mathrm{O}_{2}, 5 \% \mathrm{CO}_{2}$, and $93 \% \mathrm{~N}_{2}$ $[18,19]$. The infected red blood cells (RBCs) were transferred into a freshly prepared complete medium to propagate the culture. After $72 \mathrm{~h}$ incubation, the cultures were preserved $\left(-20^{\circ} \mathrm{C}\right)$, and the parasites were harvested. The thin blood smears were prepared and fixed with methanol and stained with $10 \%$ Giemsa for $30 \mathrm{~min}$ to evaluate the parasites' growth stage. The parasitemia was examined under the microscope, and $\mathrm{IC}_{50}$ was determined by plotting the latex concentration on the percentage of growth inhibition. Percentage growth inhibition of the parasites was determined by using the following formula $[18,25]$. 
$\%$ of growth inhibition $=\frac{(\text { mean parasitemia of control }- \text { mean parasitemia of the sample }) \times 100}{(\text { mean parasitemia of control })}$.

2.6. Parasites Inoculation. Plasmodium berghei ANKA strain was used for induction of malaria in experimental mice. The parasites were maintained by intraperitoneal serial passage of blood, and the parasitemia level (30-37\%) of P. berghei infected donor mice was determined [26, 27]. The donor mouse was anaesthetized by pentobarbitone at $150 \mathrm{mg} / \mathrm{kg}$ intraperitoneally (i.p.). Then, infected blood was collected by cardiac puncture into a heparinized vacutainer tube containing trisodium citrate $(0.5 \%)$. The blood was then diluted in normal saline $(0.9 \%)$, so that the final suspension would have about $1 \times 10^{7}$ parasitized red blood cells (PRBCs) in $0.2 \mathrm{ml}$ suspension $[17,18]$. Each mouse was infected intraperitoneally with $0.2 \mathrm{ml}$ of $1 \times 10^{7} \mathrm{P}$. berghei parasitized RBCs.

2.7. Dosing and Grouping of the Animals. The mice were randomly divided into five groups $(n=6)$. Group I (negative control) was treated with $10 \mathrm{mg} / \mathrm{kg} 2 \%$ Tween-80 in distilled water (TW80). Groups II, III, and IV were treated with 200, 400 , and $600 \mathrm{mg} / \mathrm{kg}$ doses of the leaf latex, respectively. Group V was treated with the standard drug, chloroquine $(25 \mathrm{mg} / \mathrm{kg})[17,20]$. Effective dose selection was calculated as per the oral acute toxicity test of the Organisation for Economic Co-operation and Development guidelines and pilot experiments. Since there were no observed signs of toxicity at $2000 \mathrm{mg} / \mathrm{kg}, 1 / 20^{\text {th }}(100 \mathrm{mg} / \mathrm{kg}), 1 / 10^{\text {th }}(200 \mathrm{mg} /$ $\mathrm{kg}$ ), and $1 / 5^{\text {th }}(400 \mathrm{mg})$ of $2000 \mathrm{mg} / \mathrm{kg}$ doses were considered for the pilot test. After the pilot experiment, we increased the doses until we get an effective dose. Accordingly, 200, 400, and $600 \mathrm{mg} / \mathrm{kg}$ doses were considered effective doses to be considered in the main experiment.

2.8. Antimalarial Activity of the Leaf Latex of A. weloensis in the Curative Test (Rane's Test). On the first day (day 0), the mice were injected intraperitoneally with a standard inoculum of $1 \times 10^{7} P$. berghei infected erythrocytes. After seventy-two hours, the mice were randomly assigned into five groups $(n=6)$. Group I was treated with vehicle; groups II, III, and IV were treated three doses of the latex of A. weloensis, respectively. Group V was treated with chloroquine daily for five days. Thin blood films were prepared from each mouse's tail blood daily for five days to determine parasitemia levels and mean survival time for each group $[17,18,27]$.

2.9. Antimalarial Activity of the Leaf Latex of A. weloensis in the Prophylactic Test. Mice were randomly assigned into five groups $(n=6)$ and treated with a single dose according to their respective grouping. Then, after $24 \mathrm{~h}$ (day 0 ), each mouse was injected intraperitoneally with $0.2 \mathrm{ml}$ infected blood containing $1 \times 10^{7} \mathrm{P}$. berghei parasitized RBCs. After $72 \mathrm{~h}$ (day 3 postinfection), blood samples were collected from each mouse's tip tail, and slides were prepared. Then, $\%$ inhibition, parasitemia level, and survival time were determined [17].

2.10. Peripheral Blood Smears Preparation. Thin smears of blood were made from each mouse's tail. The smears were applied on microscopic slides, and the blood was drawn evenly across a second slide to make thin blood films and allowed to dry at room temperature. Then, they were fixed with absolute methanol and stained with $10 \%$ Giemsa stain $(\mathrm{pH}=7.2)$ for $15 \mathrm{~min}$.

2.11. Parasitemia Determination. Each stained slide for each mouse was examined under a microscope. The parasitemia level was determined by counting the number of parasitized erythrocytes in random fields of the microscope. Percent parasitemia and percent suppression were calculated by using the following formula.

$$
\begin{aligned}
& \% \text { of parasitemia }=\frac{(\text { number of parasitized RBC }) \times 100}{(\text { total number of RBC })}, \\
& \% \text { of suppression }=\frac{(\text { mean parasitemia of negative control }- \text { mean parasitemia of the treated group }) \times 100}{(\text { mean parasitemia of negative control })} .
\end{aligned}
$$

2.12. Determination of Mean Survival Time. Mean survival time (MST) is another parameter that is commonly used to evaluate the efficacy of antimalarial plant materials. Mortality was monitored daily, and the number of the days from the time of infection up to death was recorded for each mouse in the treatment and control groups throughout the follow-up period. The MST was calculated for each group by using the following formula.

$$
\text { MST }=\frac{\text { sum of survival time of all mice in a group (days) }}{\text { total number of mice in that group }} .
$$

2.13. Packed Cell Volume Measurement. The packed cell volume (PCV) was measured to predict the effectiveness of the test latex in preventing hemolysis from the high level of 
parasitemia. Blood was collected from each mouse's tail in heparinized microhematocrit capillary tubes by filling threequarters of its volume. The tubes were sealed by sealant and placed in a microhematocrit centrifuge with the closed ends outwards.

The blood was then centrifuged at 12,000 rpm for $15 \mathrm{~min}$. The tubes were then taken out of the centrifuge, and PCV was determined using a standard microhematocrit reader. The PCV of each mouse was then measured before infection and on day four after infection using the formula $[17,20,26]$.

$$
\mathrm{PCV}=\frac{\text { (volume of erythrocytes in a given volume of blood) }}{\text { (total blood volume) }}
$$

2.14. Determination of Bodyweight and Temperature Changes. The bodyweights of the mice were determined to observe whether the leaf latex was prevented weight loss for Peter's test. The bodyweight of each mouse was measured before infection (day 0) and on day 4 using a sensitive digital weighing balance. Rectal temperature was also measured before infection, four hours after infection, and then daily by a digital thermometer.

2.15. Statistical Analysis. The results of the study were expressed as the mean \pm standard error of the mean. Statistical analysis of the data was carried out with a one-way analysis of variance followed by the Tukey post hoc multiple comparison test. Significant differences were set at $p<0.05$.

\section{Results}

3.1. Acute Toxicity. The mice were observed for gross signs of toxicities such as loss of appetite, hair erection, lacrimation, tremors, convulsions, salivation, diarrhea, and mortality during the experiment. Nonetheless, in the acute toxicity test, no sign of toxicity or mortality was observed in mice after oral administration of the leaf latex at $5000 \mathrm{mg} / \mathrm{kg}$ doses, signifying that $\mathrm{LD}_{50}$ was greater than $5000 \mathrm{mg} / \mathrm{kg}$.

3.2. Antioxidant Activity of the Leaf Latex of Aloe weloensis. The antioxidant capacity of the latex was evaluated using the DPPH-free radical assay method. Qualitative detection showed that the color of the test solution changed from violet to a slightly yellow color. The finding of the study showed that antioxidant activity $(p<0.001)$ of the latex was concentration-dependent with an $\mathrm{IC}_{50}$ value of $10.25 \mu \mathrm{g} / \mathrm{ml}$ (Table 1).

3.3. The Effect of the Leaf Latex of A. weloensis on P. falciparum Growth in Culture. After $72 \mathrm{~h}$ incubation, the latex of A. weloensis potentially inhibited $(p<0.001)$ the growth of the 3D7 strain of $P$. falciparum. The finding showed that the latex was active against $P$. falciparum parasites, and growth inhibition was dose-dependent (Figure 1). The $\mathrm{IC}_{50}$ of the latex and chloroquine was 9.14 and $0.12 \mu \mathrm{g} / \mathrm{ml}$, respectively.
TABLE 1: Percentage of the free radical scavenging activity of the leaf latex of Aloe weloensis.

\begin{tabular}{lcc}
\hline \multirow{2}{*}{ Concentration $(\mu \mathrm{g} / \mathrm{ml})$} & \multicolumn{2}{c}{ \% of inhibition } \\
& Ascorbic acid & Leaf latex \\
\hline 12.5 & $26.03 \pm 0.16$ & $9.21 \pm 0.37$ \\
25 & $37.82 \pm 0.23$ & $21.67 \pm 0.71$ \\
50 & $54.56 \pm 0.52$ & $33.14 \pm 0.53$ \\
100 & $70.21 \pm 0.32$ & $47.01 \pm 0.41$ \\
200 & $79.38 \pm 0.45$ & $68.01 \pm 0.31$ \\
400 & $95.13 \pm 0.34$ & $83.54 \pm 0.27$ \\
IC50 $(\mu \mathrm{g} / \mathrm{ml})$ & 2.97 & 10.25 \\
\hline \multicolumn{2}{l}{ The data are expressed as mean \pm standard error of the mean $(n=3)}$.
\end{tabular}

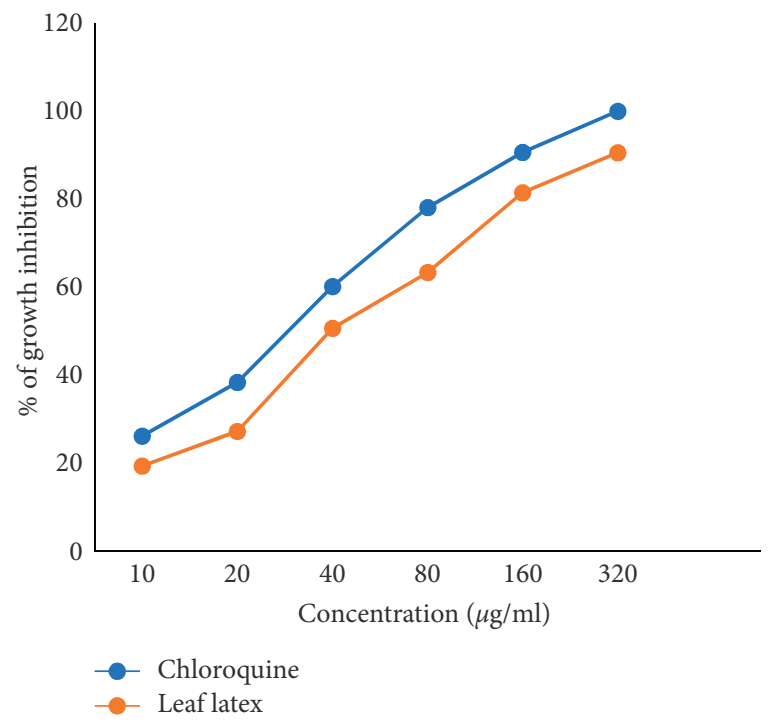

FIgURE 1: P. falciparum growth inhibition effect of the leaf latex of A. weloensis.

3.4. The Effect of the LeafLatex of Aloe weloensis in the Curative Test. The finding showed that parasitemia reduction was significant $(p<0.001)$ at 200,400 , and $600 \mathrm{mg} / \mathrm{kg}$ doses of the latex with suppression of $36 \%, 58 \%$, and $74 \%$, respectively (Table 2). The result showed that all doses of the latex endowed the curative effect as compared to the control. The curative effect of $200 \mathrm{mg} / \mathrm{kg}$ dose was significantly $(p<0.01)$ lower than chloroquine $(p<0.001)$. All tested doses of the latex significantly $(p<0.01)$ improved the mean survival time of the mice compared to the negative control. Nonetheless, the survival time of the mice treated with the lowest dose $(200 \mathrm{mg} / \mathrm{kg})$ was significantly $(p<0.01)$ lower than chloroquine.

3.5. The Effect of A. weloensis Leaf Latex on PCV, Rectal Temperature, and Bodyweight. In this study, the leaf latex at 400 and $600 \mathrm{mg} / \mathrm{kg}$ doses significantly $(p<0.01)$ prevented packed cell volume and reduced rectal temperature of $P$. berghei-infected mice compared to the vehicle control. Besides, $25 \mathrm{mg} / \mathrm{kg}$ chloroquine significantly $(p<0.001)$ prevented PCV and rectal temperature (Table 3 ). The prevention of bodyweight reduction was significant at the 
TABle 2: Parasitemia level, \% suppression, and survival time of infected mice treated by the leaf latex of $A$. weloensis in the curative test.

\begin{tabular}{lccc}
\hline Groups & \% parasitemia & \% suppression & Survival time (days) \\
\hline $10 \mathrm{ml} / \mathrm{kg} \mathrm{NC}$ & $76.85 \pm 0.61$ & 00.00 & $8.12 \% \pm 0.41$ \\
$25 \mathrm{mg} / \mathrm{kg} \mathrm{CQ}$ & $00.00 \pm 0.00$ & $100.00^{\mathrm{a} 3 \mathrm{~b} 3 \mathrm{c} 2 \mathrm{~d} 2}$ & $30.00 \pm 0.00^{\mathrm{a} 3 \mathrm{~b} 2}$ \\
$200 \mathrm{mg} / \mathrm{kg} \mathrm{LL}$ & $40.37 \pm 0.71^{\mathrm{a} 3 \mathrm{e} 2}$ & $36.17^{\mathrm{a} 3 \mathrm{e} 3}$ & $12.72 \pm 0.45^{\mathrm{a} 2 \mathrm{e} 2}$ \\
$400 \mathrm{mg} / \mathrm{kg} \mathrm{LL}$ & $30.25 \pm 0.45^{\mathrm{a} 3 \mathrm{e} 2}$ & $57.69^{\mathrm{a} 3 \mathrm{e} 2}$ & $20.14 \pm 0.62^{\mathrm{a} 2}$ \\
$600 \mathrm{mg} / \mathrm{kg} \mathrm{LL}$ & $23.65 \pm 0.57^{\mathrm{a} 3 \mathrm{e} 1}$ & $73.51^{\mathrm{a} 3 \mathrm{e} 2}$ & $24.87 \pm 0.73^{\mathrm{a} 2}$ \\
\hline
\end{tabular}

Data are expressed as mean \pm standard error of the mean; $n=6 .{ }^{a}$ Compared to vehicle; ${ }^{b}$ compared to $200 \mathrm{mg} / \mathrm{kg}$; ${ }^{\mathrm{c}}$ compared to $400 \mathrm{mg} / \mathrm{kg}$; ${ }^{\mathrm{d}}$ compared to $600 \mathrm{mg} / \mathrm{kg}$; ${ }^{\mathrm{e}}$ compared to $25 \mathrm{mg} / \mathrm{kg} \mathrm{CQ} .{ }^{1} p<0.05,{ }^{2} p<0.01$, and ${ }^{3} p<0.001$ with respect to vehicle control. CQ, chloroquine; LL, leaf latex; NC, negative control.

TABLE 3: Packed cell volume, rectal temperature, and the bodyweight of infected mice treated by the leaf latex of $A$. weloensis in the curative test.

\begin{tabular}{lcccccc}
\hline \multirow{2}{*}{ Groups } & \multicolumn{2}{c}{ PCV } & \multicolumn{2}{c}{ Temperature } & \multicolumn{2}{c}{ Bodyweight } \\
& Day 0 & Day 4 & Day 0 & Day 4 & Day 0 & Day 4 \\
\hline $10 \mathrm{ml} / \mathrm{kg} \mathrm{NC}$ & $49.60 \pm 1.36$ & $40.60 \pm 1.81$ & $37.12 \pm 0.16$ & $29.64 \pm 0.36$ & $28.80 \pm 0.37$ & $24.760 \pm 0.23$ \\
$25 \mathrm{mg} / \mathrm{kg} \mathrm{CQ}$ & $48.12 \pm 0.10$ & $53.20 \pm 0.37^{\mathrm{a} 3 \mathrm{~b} 1}$ & $35.60 \pm 0.73$ & $37.42 \pm 0.12^{\mathrm{a} 3}$ & $27.60 \pm 0.51$ & $32.60 \pm 0.73^{\mathrm{a} 3}$ \\
$200 \mathrm{mg} / \mathrm{kg} \mathrm{LL}$ & $48.00 \pm 0.71$ & $42.00 \pm 0.95^{\mathrm{c} 1}$ & $36.58 \pm 0.13$ & $32.38 \pm 0.31^{\mathrm{c} 1}$ & $27.00 \pm 0.71$ & $27.24 \pm 0.37^{\mathrm{a} 1}$ \\
$400 \mathrm{mg} / \mathrm{kg} \mathrm{LL}$ & $48.80 \pm 0.73$ & $46.80 \pm 0.63^{\mathrm{a} 2}$ & $36.54 \pm 0.18$ & $34.36 \pm 0.31^{\mathrm{a} 2}$ & $26.80 \pm 0.37$ & $29.60 \pm 1.52^{\mathrm{a} 2}$ \\
$600 \mathrm{mg} / \mathrm{kg} \mathrm{LL}$ & $49.00 \pm 0.56$ & $47.10 \pm 1.08^{\mathrm{a} 2}$ & $36.54 \pm 0.18$ & $36.02 \pm 0.07^{\mathrm{a} 2}$ & $28.60 \pm 0.51$ & $31.80 \pm 0.68^{\mathrm{a} 2}$ \\
\hline
\end{tabular}

Data are expressed as means \pm standard error of the mean; $n=6 .{ }^{\mathrm{a}}$ Compared to vehicle; ${ }^{\mathrm{b}}$ compared to $200 \mathrm{mg} / \mathrm{kg} ;{ }^{\mathrm{c}} \mathrm{compared}$ to $25 \mathrm{mg} / \mathrm{kg} \mathrm{CQ} .{ }^{1} p<0.05$, ${ }^{2} p<0.01$, and ${ }^{3} p<0.001$ with respect to vehicle control. Day 0 , weight, temperature, and packed cell volume pretreatment on day zero. Day 4 , posttreatment on day five. CQ, chloroquine; LL, leaf latex; NC, negative control; PCV, packed cell volume.

middle and upper doses of the treatment group $(p<0.05$ at 200 and $p<0.01$ at 400 and $600 \mathrm{mg} / \mathrm{kg}$ ) compared to the curative test's control.

3.6. The Effect of the Leaf Latex of Aloe weloensis in the Prophylactic Test. The finding showed that the leaf latex at the doses of $200 \mathrm{mg} / \mathrm{kg}(p<0.05)$ and 400 and $600 \mathrm{mg} / \mathrm{kg}$ $(p<0.01)$ significantly reduced the parasitemia level in the prophylactic test compared to the vehicle control. Parasitemia reduction was dose-dependent, and the percentage of suppression was increased with increasing the doses of the leaf latex of $A$. weloensis. Similarly, all tested doses of A. weloensis leaf latex significantly $(p<0.01)$ increased the mean survival time of the mice. The survival time of the mice treated with the latex at $200 \mathrm{mg} / \mathrm{kg}$ dose was significantly $(p<0.01)$ lower than the standard drug (Table 4$)$.

\section{Discussion}

The antimalarial activity of the leaf latex of Aloe weloensis was evaluated against Plasmodium parasites. The in vitro test was evaluated on the chloroquine-sensitive 3D7 strain of the parasite. In contrast, in vivo tests were evaluated on $P$. berghei infected mice since $P$. berghei produce diseases similar to human Plasmodium infection and sensitivity to standard drug chloroquine $[4,17,28]$.

In this study, the leaf latex showed the potent antimalarial activity against the 3D7 strain of $P$. falciparum. Parasite inhibition was dose-dependent, with $\mathrm{IC}_{50}$ values of the leaf latex and chloroquine 9.14 and $0.02 \mu \mathrm{g} / \mathrm{mL}$, respectively. According to a previous study by Satish and Sunita [19], the leaf latex of $A$. weloensis was active $\left(\mathrm{IC}_{50}=5-50 \mu \mathrm{g} / \mathrm{ml}\right.$ ) against the 3D7 strain of $P$. falciparum. The parasite growth
TABle 4: Parasitemia level, \% suppression, and survival time of infected mice treated by the leaf latex of Aloe weloensis in the prophylactic test.

\begin{tabular}{lccc}
\hline Group & $\%$ parasitemia & $\begin{array}{c}\% \\
\text { suppression }\end{array}$ & $\begin{array}{c}\text { Survival time } \\
\text { (days) }\end{array}$ \\
\hline $10 \mathrm{ml} / \mathrm{kg} \mathrm{NC}$ & $65.31 \pm 0.17$ & - & $5.72 \pm 0.42$ \\
$25 \mathrm{mg} / \mathrm{kg} \mathrm{CQ}$ & $00.0 \pm 00^{\mathrm{a} 3 \mathrm{~b} 2}$ & 100 & $30.45 \pm 0.18^{\mathrm{abb} 2}$ \\
$200 \mathrm{mg} / \mathrm{kg} \mathrm{LL}$ & $27.42 \pm 0.23^{\mathrm{a} \text { cld } 1 \mathrm{e} 2}$ & 37.87 & $8.21 \pm 0.15^{\mathrm{a} 1 \mathrm{de} 2}$ \\
$400 \mathrm{mg} / \mathrm{kg} \mathrm{LL}$ & $16.52 \pm 0.18^{\mathrm{a} 2 \mathrm{~b} 1}$ & 46.29 & $14.10 \pm 0.31^{\mathrm{a} 2}$ \\
$600 \mathrm{mg} / \mathrm{kg} \mathrm{LL}$ & $12.12 \pm 0.41^{\mathrm{a} \mathrm{b} 1}$ & 56.68 & $17.50 \pm 0.22^{\mathrm{abb} 1}$ \\
\hline
\end{tabular}

Data are expressed as means \pm standard error of the mean; $n=6 .{ }^{\mathrm{a} C o m p a r e d}$ to vehicle; ${ }^{\mathrm{b}}$ compared to $200 \mathrm{mg} / \mathrm{kg}$; ${ }^{\mathrm{c}}$ compared to $400 \mathrm{mg} / \mathrm{kg}$; ${ }^{\mathrm{d}}$ compared to $600 \mathrm{mg} / \mathrm{kg}$; ${ }^{\mathrm{e}}$ compared to $25 \mathrm{mg} / \mathrm{kg} \mathrm{CQ} .{ }^{1} p<0.05,{ }^{2} p<0.01$, and ${ }^{3} p<0.001$ with respect to vehicle control. $C Q$, chloroquine; $L L$, leaf latex; $N C$, negative control.

inhibition calls for further investigation in the curative and prophylactic model against $P$. berghei-infected mice, since in vivo models allow the possible bioactivation and the likelihood of the immune system to eradicate the infection, unlike in vitro studies $[4,6,27]$.

Plant extracts are considered active when reduction or percentage suppression in parasitemia is $\geq 30 \%$ or significant prolonging the survival time of treated mice compared to the vehicle control [29-31]. Thus, the leaf latex of A. weloensis was found to be active against $P$. berghei infected mice.

A curative test was employed in the current study to assess the leaf latex effect in late Plasmodium infection. The finding showed that the curative effect of the latex was significant $(p<0.001)$ at all doses compared to the vehicle with \% suppression of $36 \%(200 \mathrm{mg} / \mathrm{kg}), 58 \%(400 \mathrm{mg} / \mathrm{kg})$, and $74 \%(600 \mathrm{mg} / \mathrm{kg})$. This confirmed that the leaf latex of A. weloensis endowed efficacy in the late stages of Plasmodium infection. The relatively less chemosuppression activity 
(36\%) at $200 \mathrm{mg} / \mathrm{kg}$ dose of the leaf latex is possibly due to less accumulative efficacy to bring high chemosuppression. The latex at the $400 \mathrm{mg} / \mathrm{kg}(58 \%)$ and $600 \mathrm{mg} / \mathrm{kg}(74 \%)$ showed greater parasite suppression, implying the latex dose-dependent curative effect. Compared to the previous 4day suppressive test $(p<0.01)$ [16], the leaf latex of Aloe weloensis showed greater curative potential $(p<0.001)$ in the late stage of Plasmodium infection in the curative test.

Phytoconstituents present in the latex may block parasite growth and replication. Alkaloids endowed the antimalarial effect by blocking detoxification of heme and protein synthesis in P. falciparum [32, 33]. Quinine is an alkaloidal antimalarial drug isolated from Cinchona bark. It is useful in treating multidrug-resistant malaria and serving as the lead compound for chloroquine derivatives [34]. Phytosterols and flavonoids showed an outstanding activity against Plasmodium parasites by boosting host immunity [35].

In this study, all doses of the latex significantly $(p<0.01)$ improved the mean survival time of the mice compared to the negative control in the curative test. This finding might indicate that the latex suppressed $P$. berghei and reduced the parasite's overall pathologic effect on the mice. The survival time of the mice treated by various doses of the latex longer in the curative test is compared to the previous 4-day suppressive test [16], possibly due to the longest mean survival time of the mice strongly associated with the maximum parasitemia inhibition. According to the previous study by Basir et al., the leaf latex of $A$. weloensis was active as the latex prolonged mean survival time beyond 12 days [36].

In addition, packed cell volume and rectal temperature of mice were used to predict the effectiveness of the test compounds. Contrary to humans, mice's body temperature was decreased while increasing parasitemia due to a decrease in the metabolism of infected mice $[6,36]$. In this study, the latex doses at 400 and $600 \mathrm{mg} / \mathrm{kg}$ showed a significant $(p<0.01)$ protective effect in rectal temperature of $P$. berghei infected mice. This could probably be due to the latex's preventive effects in some pathological processes that cause a reduction in internal body temperature and augment the immune system and metabolic rate of infected mice.

Packed cell volume reduction is one feature of $P$. berghei infected mice and was determined to evaluate the effectiveness of Aloe weloensis. In both humans and mice, escalating parasitemia destroys infected RBCs, clearance of uninfected RBCs, and erythropoietic suppression [37]. Packed cell volume was monitored before infection and on day four after infections to predict the effectiveness of the study plant. The present study showed that medium and high doses of the latex significantly $(p<0.01)$ prevented PCV reduction compared to vehicle control. This effect is in line with the pack cell volume protection effect of the Aloe megalacantha [38]. However, the lower dose was devoid of the significant prevention effect of red blood cells hemolysis. This might be due to the low concentration of bioactive molecules at the lower dose relative to the other doses. The prevention of packed cell volume reduction might be due to the leaf latex's antiplasmodial effect against the parasitized $\mathrm{RBCs}$ and the causative parasite, thereby sustaining the availability of the new RBCs produced in the bone marrow $[39,40]$.

The bodyweight loss in the experimental animals is due to the appetite-suppressing effects of the parasite [36]. Similarly, the present finding showed that the latex of A. weloensis was significant in preventing $P$. berghei-induced weight loss in mice at all tested doses. The findings of this study showed that packed cell volume, rectal temperature, and bodyweight of infected mice were concordant with the previous 4-day suppressive test [16].

In this study, the result showed significant dose-dependent parasitemia reduction of all doses of the leaf latex of A. weloensis in the prophylactic test. Parasitemia suppression was $38 \%$ at $200 \mathrm{mg} / \mathrm{kg}, 46 \%$ at $400 \mathrm{mg} / \mathrm{kg}$, and $57 \% 600 \mathrm{mg} /$ $\mathrm{kg}$ doses of the latex. The mean survival time of the mice treated by all doses of the latex was significantly prolonged relative to the control, but the survival time of the mice treated by low dose was significantly lower than the standard drug. The result of this study showed that the leaf latex of the plant might prevent transmission of the Plasmodium parasite.

\section{Conclusion}

The findings of the present study confirmed the prominent antimalarial activity of the leaf latex of Aloe weloensis against the 3D7 strain of $P$. falciparum and $P$. berghei and corroborate its use in folk medicine. The medium and higher doses of the latex showed a greater prophylactic and curative effect. Therefore, an advanced study is required for organ toxicity study and to identify, characterize, and isolate the bioactive compounds that possess the antimalarial activity.

\section{Abbreviations}

CQ: $\quad$ Chloroquine

DPPH: Diphenyl-1-picrylhydrazine

IC50: Inhibitory concentration 50

LD50\%: Lethal dose 50

LL: $\quad$ Leaf latex

MST: Mean survival time

NC: $\quad$ Negative control

OECD: Organisation for Economic Co-operation and Development

PCV: Packed cell volume

RBCs: Red blood cells

PRBCs: Parasitized red blood cells

TW80: Tween-80 in distilled water.

\section{Data Availability}

The datasets used/or analyzed to support the findings of this study are available from the corresponding author upon request.

\section{Ethical Approval}

Ethical approval was obtained from the Ethical Review Committee of College of Medicine and Health Sciences, 
Wollo University (Approval number: WU Phar/325/12). The study was conducted according to OECD Guidelines and the Guide for the Care and Use of Laboratory Animals.

\section{Conflicts of Interest}

The authors declare that they have no conflicts of interest.

\section{Authors' Contributions}

Gedefaw Getnet Amare, Amsalu Degu, Zemene Demelash Kifle, and Peter Njogu were involved in the study's design, the actual experiment, analysis of the data, and write-up of the manuscript. All authors have approved the manuscript.

\section{Acknowledgments}

The authors are grateful to Wollo University for funding the study.

\section{References}

[1] S. Edwards, I. Da-Costa-Rocha, M. J. Lawrence, C. Cable, and M. Heinrich, "Use and efficacy of herbal medicines: part 1-historical and traditional use," Acute Pain, vol. 10, p. 00, 2019.

[2] A. Y. M. Kitua, "HM Malaria control in Africa and the role of traditional medicine," in Traditional Medicinal Plants and Malaria, M. Willcox, G. Bodeker, P. Rasoanaivo, and J. Addae-Kyereme, Eds., pp. 2-20, CRC Press, Boca Raton, FL, USA, 1st edition, 2004.

[3] S. De Ridder, F. Van der Kooy, and R. Verpoorte, "Artemisia annua as a self-reliant treatment for malaria in developing countries," Journal of Ethnopharmacology, vol. 120, no. 3, pp. 302-314, 2008.

[4] D. A. Fidock, P. J. Rosenthal, S. L. Croft, R. Brun, and S. Nwaka, "Antimalarial drug discovery: efficacy models for compound screening," Nature Reviews Drug Discovery, vol. 3, no. 6, pp. 509-520, 2004.

[5] A. Blessing, M. Abdulahi, K. Yusuf, and O. Olofu, "Antimalarial activity of crude extract and fractions of Phyllanthus amarus in plasmodium berghei-infected mice," European Journal of Medicinal Plants, vol. 24, no. 3, pp. 1-11, 2018.

[6] B. Kalra, S. Chawla, P. Gupta, and N. Valecha, "Screening of antimalarial drugs: an overview," Indian Journal of Pharmacology, vol. 38, no. 1, p. 5, 2006.

[7] A. Mukherjee, S. Bopp, P Magistrado et al., "Artemisinin resistance without pfkelch13 mutations in Plasmodium falciparum isolates from Cambodia," Malaria Journal, vol. 16, no. 1, pp. 195-212, 2017.

[8] World Health Organization, World Malaria Report 2017, WHO Press, Geneva, Switzerland, 2017.

[9] O. Tobias, A. O. Apinjoh, P. K. Vincent et al., "Genetic diversity and drug resistance surveillance of Plasmodium falciparum for malaria elimination: is there an ideal tool for resource-limited sub-Saharan Africa?" Malaria Journal, vol. 18, no. 217, 2019.

[10] W.-H. Pan, X.-Y. Xu, N. Shi, S. Tsang, and H.-J. Zhang, "Antimalarial activity of plant metabolites," International Journal of Molecular Sciences, vol. 19, no. 5, p. 1382, 2018.

[11] C. K. Chinsembu, "Plants as antimalarial agents in subsaharan Africa," Acta Tropica, vol. 152, pp. 32-48, 2015.

[12] B. Bekono, F. Kang, P. Onguéné et al., "The potential of antimalarial compounds derived from African medicinal plants: a review of pharmacological evaluations from 2013 to 2019," Malaria Journal, vol. 19, pp. 183-235, 2020.

[13] B. Salehi, S. Albayrak, H. Antolak et al., "Aloe genus plants: from farm to food applications and phytopharmacotherapy," International Journal of Molecular Sciences, vol. 19, no. 9, p. 2843, 2018.

[14] Y. K. Emiru, E. A. Siraj, T. T. Teklehaimanot, and G. G. Amare, "Antibacterial potential of Aloe weloensis (aloeacea) leaf latex against gram-positive and gram-negative bacteria strains," International Journal of Microbiology, vol. 2019, Article ID 328238, 4 pages, 2019.

[15] G. Chekole, "Ethnobotanical study of medicinal plants used against human ailments in Gubalafto District, Northern Ethiopia," Journal of Ethnobiology and Ethnomedicine, vol. 13, no. 1, p. 55, 2017.

[16] T. Teka, T. Awgichew, and H. Kassahun, "Antimalarial activity of the leaf latex of Aloe weloensis (aloaceae) against plasmodium berghei in mice," Journal of Tropical Medicine, vol. 2020, Article ID 1397043, 7 pages, 2020.

[17] D. Misganaw, E. Engidawork, and T. Nedi, "Evaluation of the anti-malarial activity of crude extract and solvent fractions of the leaves of olea europaea (oleaceae) in mice," BMC Complementary and Alternative Medicine, vol. 19, no. 1, p. 171, 2019.

[18] S. D. D. Attemene, S. Beourou, K. Tuo et al., "Antiplasmodial activity of two medicinal plants against clinical isolates of Plasmodium falciparum and Plasmodium berghei infected mice," Journal of Parasitic Diseases, vol. 42, no. 1, pp. 68-76, 2018.

[19] P. V. V. Satish and K. Sunita, "Antimalarial efficacy of Pongamia pinnata (L) Pierre against Plasmodium falciparum (3D7 strain) and plasmodium berghei (ANKA)," BMC Complementary and Alternative Medicine, vol. 17, no. 1, p. 458, 2017.

[20] S. Asrade, Y. Mengesha, G. Moges, and D. A. Gelayee, "In vivo antiplasmodial activity evaluation of the leaves of Balanites rotundifolia (Van Tiegh.) blatter (Balanitaceae) against plasmodium berghei," Journal of Experimental Pharmacology, vol. 9, pp. 59-66, 2017.

[21] N. R. Council, Guide for the Care and Use of Laboratory Animals, National Academies Press, Washington, DC, USA, 2010.

[22] O. Ocde, "Acute oral toxicity: up and down procedure," OECD Guideline for the Testing of Chemicals, vol. 425, pp. 1-2, 2008.

[23] L. K. MacDonald-Wicks, L. G. Wood, and M. L. Garg, "Methodology for the determination of biological antioxidant capacity in vitro: a review," Journal of the Science of Food and Agriculture, vol. 86, no. 13, pp. 2046-2056, 2006.

[24] C. Sánchez-Moreno, "Review: methods used to evaluate the free radical scavenging activity in foods and biological systems," Food Science and Technology International, vol. 8, no. 3, pp. 121-137, 2002.

[25] S. Panda, J. R. Rout, P. Pati, M. Ranjit, and S. L. Sahoo, "Antimalarial activity of Artemisia nilagirica against Plasmodium falciparum," Journal of Parasitic Diseases, vol. 42, no. 1, pp. 22-27, 2018.

[26] A. H. Al-Adhroey, Z. M. Nor, H. M. Al-Mekhlafi, A. A. Amran, and R. Mahmud, "Antimalarial activity of methanolic leaf extract of Piper betle L," Molecules.vol. 16, no. 1, pp. 107-118, 2011.

[27] L. Bantie, S. Assefa, T. Teklehaimanot, and E. Engidawork, "In vivo antimalarial activity of the crude leaf extract and solvent fractions of Croton macrostachyus Hocsht. (Euphorbiaceae) 
against Plasmodium berghei in mice," BMC Complementary and Alternative Medicine, vol. 14, no. 1, p. 79, 2014.

[28] S. Asmamaw Tadesse and Z. Birhanu Wubneh, "Antimalarial activity of Syzygium guineense during early and established Plasmodium infection in rodent models," BMC Complementary Medicine and Therapies, vol. 5, no. 1, p. 21, 2017.

[29] E. M. Birru, M. Geta, and A. E. Gurmu, "Antiplasmodial activity of Indigofera spicata root extract against Plasmodium berghei infection in mice," Malaria Journal, vol. 16, no. 1, p. 198, 2017.

[30] S. Fentahun, E. Makonnen, T. Awas, and M. Giday, "In vivo antimalarial activity of crude extracts and solvent fractions of leaves of Strychnos mitis in plasmodium berghei infected mice," BMC Complementary and Alternative Medicine, vol. 17, no. 1, p. 13, 2017.

[31] M. Adugna, T. Feyera, W. Taddese, and P. Admasu, "In vivo anti-malarial activity of crude extract of aerial part of artemisia abyssinica against plasmodium berghei in mice," Global Journal of Pharmacology, vol. 8, no. 4, pp. 557-565, 2014.

[32] M. Mojarrab, A. Shiravand, A. Delazar, and F. Heshmati Afshar, "Evaluation of in vitro antimalarial activity of different extracts of artemisia aucheri boiss. and A. armeniaca lam. and fractions of the most potent extracts," The Scientific World Journal, vol. 2014, Article ID 825370, 6 pages, 2014.

[33] J. B. C. Soares, D. Menezes, M. A. Vannier-Santos et al., "Interference with hemozoin formation represents an important mechanism of schistosomicidal action of anti-malarial quinoline methanols," PLoS Neglected Tropical Diseases, vol. 3, no. 7, 2009.

[34] P. F. Uzor, "Alkaloids from plants with anti-malarial activity: a review of recent studies," Evidence-Based Complementary and Alternative Medicine, vol. 2020, Article ID 8749083, 17 pages, 2020.

[35] S. Aherne, T. Daly, T. O’Connor, and N. O’Brien, "Immunomodulatory effects of $\beta$-sitosterol on human jurkat T cells," Planta Medica, vol. 73, no. 09, p. 11, 2007.

[36] R. Basir, S. F. Rahiman, K Hasballah et al., "Plasmodium berghei ANKA infection in ICR mice as a model of cerebral malaria," Iranian Journal of Parasitology, vol. 7, no. 4, pp. 62-74, 2012.

[37] J. E. Okokon, B. N. Ita, and A. E. Udokpoh, "The in-vivo antimalarial activities ofUvaria chamaeandHippocratea africana," Annals of Tropical Medicine \& Parasitology, vol. 100, no. 7, pp. 585-590, 2006.

[38] G. Hintsa, G. G. Sibhat, and A. Karim, "Evaluation of antimalarial activity of the leaf latex and TLC isolates from Aloe megalacantha Baker in Plasmodium berghei infected mice," Evidence-Based Complementary and Alternative Medicine, vol. 2019, Article ID 6459498, 9 pages, 2019.

[39] A. A. Lamikanra, D. Brown, A. Potocnik, C. Casals-Pascual, J. Langhorne, and D. J. Roberts, "Malarial anemia: of mice and men," Blood, vol. 110, no. 1, pp. 18-28, 2007.

[40] K. Kaur, M. Jain, T. Kaur, and R. Jain, "Antimalarials from nature," Bioorganic \& Medicinal Chemistry, vol. 17, no. 9, pp. 3229-3256, 2009. 